\title{
ECG Body Surface Mapping (BSM) in Type 1 Diabetic Patients
}

\author{
D. ŽĎÁRSKÁ, P. PELÍŠKOVÁ, J. CHARVÁT, J. SLAVÍČEK ${ }^{1}$, M. MLČEK ${ }^{1}$, \\ E. MEDOVÁ ${ }^{1}$, O. KITTNAR ${ }^{1}$
}

Department of Medicine, Second Medical Faculty, and ${ }^{1}$ Institute of Physiology, First Medical Faculty, Charles University, Prague, Czech Republic

Received May 10, 2006

Accepted June 20, 2006

On-line available August 22, 2006

\begin{abstract}
Summary
Diabetes mellitus is a risk factor of cardiovascular diseases. ECG of patients with diabetes mellitus type 1 (DM 1) shows tachycardia (block of parasympathetic innervation) and abnormal repolarization (increased QT interval and QT dispersion (QTd)) indicating a risk of ventricular tachycardia and sudden death in young people with DM 1. The aim of the present report was to measure 145 parameters of the heart electric field in 22 patients (14 men, 8 women) with DM 1 without complications (mean age $32.8 \pm 11.4$ years) and in 22 controls (11 men, 11 women, mean age 30.1 \pm 3.4 years). The duration of diabetes was $13.9 \pm 7.8$ years. The parameters were registered by the diagnostic system Cardiag 112.2 and statistically evaluated by the Student and Mann-Whitney test. Tachycardia $\left(86.3 \pm 2.7\right.$ beats. min $\left.^{-1}\right)$, shortening of both QRS (79.9 $\pm 1.6 \mathrm{~ms})$ and QT $(349.0 \pm 5.9 \mathrm{~ms})$ and increased QT dispersion $(115 \pm 36 \mathrm{~ms})$ were observed in DM 1 when compared with the controls (75.0 2.1 beats. min. $^{-1}$, QRS $89.9 \pm 2.7 \mathrm{~ms}$, QT $374.0 \pm 4.4 \mathrm{~ms}$, QTd $34.0 \pm 12.0 \mathrm{~ms}$, $\mathrm{p}<0.01$ ). The QTc was $415.2 \pm 4.1 \mathrm{~ms}$ in DM 1 and $401.4 \pm 6.6 \mathrm{~ms}$ in controls (NS). Other significant findings in DM 1 were: higher maximum of depolarization isopotential maps (DIPMmax) in the initial phase of QRS and less positive in the terminal phase, more negative minimum (DIPMmin) during QRS similarly as the minimum in depolarization isointegral maps (DIIMmin) and the minimum in isointegral map of the $\mathrm{Q}$ wave (Q-IIMmin), lower maximum in repolarization isopotential maps (RIPMmax) and less negative minimum (RIPMmin), more negative amplitude of Q wave (Q-IPMAM) and more pronounced spread of depolarization (activation time). Our results confirmed a decreased parasympathetic to sympathetic tone ratio (tachycardia, shortening of the activation time) and revealed different depolarization and repolarization patterns in DM 1. The differences in heart electric field parameters measured by the BSPM method in DM 1 and in the controls indicate the importance of ECG examination of diabetic patients type 1 in the prevention of cardiovascular diseases.
\end{abstract}

\section{Key words}

Diabetes mellitus type $1 \bullet \mathrm{ECG} \bullet \mathrm{VCG} \bullet$ Body surface maps

\section{Introduction}

Diabetes mellitus is associated with poor cardiovascular prognosis (Kannel et al. 1986, Charvát 2001). The diagnosis of type 1 diabetes mellitus is usually established at a relatively young age. The 
development of macrovascular changes therefore takes many years (Alberti and Zimmet 1998, Beckman et al. 2002, Pickup and Williams 2003). Twelve leads resting electrocardiogram is often falsely negative in diabetic patients with coronary artery disease (Zellweger and Pfisterer 2001). Although certain examinations might be of importance (e.g. echocardio-graphy, carotid sonography), the stress test is often necessary for myocardial ischemia detection in asymptomatic patients (Paillole et al. 1995, Charvát et al. 2004). Apart from cardiovascular morbidity type 1 diabetes mellitus is associated with microvascular complications including autonomic neuropathy (Alberti et al. 1978). The lengthening of QTc (QT corrected for heart rate) in the ECG was observed in patients with diabetes mellitus type 1 (DM 1) both with and without autonomic neuropathy suggesting that autonomic dysfunction does not contribute to hypoglycemia- induced QTc prolongation (Heller 2002).

The blood pressure variability in DM 1 patients is lower than in the controls (Ruzicska et al. 2003). The impaired parasympathetic control of heart rate was observed. No differences in vascular sympathetic control were detected (Javorka et al. 2005).

The insulin hypoglycemia in DM 1 patients causes an abnormal electrocardiogram with an increase in the QT interval and its dispersion (Heller 2002). The abnormalities in cardiac repolarization indicate a risk of ventricular tachycardia and sudden death in DM 1 patients (Marques et al. 1997). In the present report, we studied the electrocardiogram, vectorcardiogram and body surface mapping in asymptomatic DM 1 patients with the aspect to prevent cardiovascular diseases. The preliminary results have been presented elsewhere (Štěpánková et al. 2006).

\section{Patients and Methods}

\section{Patients}

Twenty-two DM 1 patients examined in 2005 and 22 healthy control subjects have been included in the study (Table 1). The duration of diabetes mellitus type 1 was $13.9 \pm 9.8$ years. The diagnosis of diabetes mellitus type 1 was based on the WHO criteria (Alberti and Zimmet 1998).

The DM 1 patients were treated with insulin applied either by a continuous subcutaneous injection (CSII) or by insulin applicators in an intensive insulin therapy. They were without any known microvascular or
Table 1. The characteristics of controls and diabetic patients type 1 (DM 1)

\begin{tabular}{lcc}
\hline & Controls & DM 1 \\
\hline Number & 22 & 22 \\
Mean age (years) & $30.1 \pm 3.4$ & $32.8 \pm 3.5$ \\
Men & 11 & 14 \\
Women & 11 & 8 \\
\hline
\end{tabular}

macrovascular complications. Their 12 leads ECGs were within normal limits. Apart from insulin, no medication was applied to the patients and healthy controls. We recorded the duration of type 1 diabetes mellitus and its long-term metabolic compensation. The long-term metabolic compensation of diabetic patients evaluated by HbAlc according to IFCC was $6.5 \pm 1.3 \%$. The average total daily insulin dosage was $46.6 \pm 10.4$ IU and was applied by CSII in 7 patients and by insulin applicators in intensive insulin therapy in 14 patients.

\section{Measurements}

The electrocardiogram (ECG), vectorcardiogram (VCG) and body surface potential maps (BSPM) isopotential, isointegral and isoarea maps - were registered altogether using the diagnostic system CARDIAG 112.2 (Pišvejcová et al. 2002). All examinations were performed in the morning between 9 to $11 \mathrm{~h}$ in order to avoid any influence of circadian rhythms (Švorc et al. 1994, 2000). Heart rate, duration of PQ, QRS, QT and QTc intervals were recorded and evaluated by 12-lead ECG.

In the VCG evaluation the Frank orthogonal lead system was used (Frank 1956). The QRS axis deviation in frontal plane was measured. The QRS-STT angles in the frontal, transversal and left sagittal planes and the shape of QRS loops were registered.

For evaluation of the QT dispersion (QTd) the QT interval was measured by 80 unipolar chest leads used for body surface potential mapping. The QT interval was measured from the start of the $\mathrm{Q}$ wave to the end of the $\mathrm{T}$ wave, QT dispersion was then defined as the difference between the maximal and minimal QT interval in any of the leads measured.

The depolarization, repolarization isopotential maps (DIPM, RIMP), isointegral depolarization and repolarization maps (DIIM, RIIM) and their maximum and minimum were recorded and evaluated by ECG body surface potential maps (BSPM). Depolarization isoarea 
Table 2. Heart rate, PQ, QRS, QT, QTd and QTc in controls and DM 1 patients

\begin{tabular}{|c|c|c|c|c|c|}
\hline & Group & $\mathbf{n}$ & Mean \pm S.E.M. & Mann-Whitney & $\mathbf{p}$ \\
\hline \multirow{2}{*}{ Heart rate $\left(\mathrm{min}^{-1}\right)$} & controls & 22 & $75 \pm 2.11$ & 113 & 0.002 \\
\hline & DM 1 & 22 & $86.32 \pm 2.67$ & & \\
\hline \multirow{2}{*}{$P Q(m s)$} & controls & 22 & $158.3 \pm 7.09$ & 219 & NS \\
\hline & DM 1 & 22 & $147.9 \pm 3.67$ & & \\
\hline \multirow{2}{*}{$Q R S(m s)$} & controls & 22 & $89.9 \pm 2.67$ & 131 & 0.009 \\
\hline & DM 1 & 22 & $79.9 \pm 1.58$ & & \\
\hline \multirow{2}{*}{$Q T(m s)$} & controls & 22 & $374.0 \pm 4.4$ & 101.5 & 0.001 \\
\hline & DM 1 & 22 & $349.0 \pm 5.9$ & & \\
\hline \multirow{2}{*}{$Q T c(m s)$} & controls & 22 & $401.4 \pm 6.1$ & 234.5 & NS \\
\hline & DM 1 & 22 & $415.2 \pm 4.1$ & & \\
\hline \multirow{2}{*}{$Q T d(m s)$} & controls & 22 & $34 \pm 12$ & 104 & 0.001 \\
\hline & DM 1 & 22 & $115 \pm 36$ & & \\
\hline
\end{tabular}

Data are means \pm S.E.M.

maps, their maximum and minimum in $\mu \mathrm{Vs}$ (isointegral maps from the beginning of QRS until $40 \mathrm{~ms}$ - DIAM $\max 40$, DIAM min 40) and depolarization areas and their maximum and minimum in $\mu \mathrm{Vs}$ (isointegral maps from the point $\mathrm{J}$ to 40 th ms - RIAM max 40 and RIAM min 40) were also examined. Isointegral minimum (Q-IIM) and amplitude (IPMAM-Q) of the Q wave as well as QT duration in chest electrodes during BSPM measurement were compared between DM 1 patients and the healthy controls. Activation time (ICHVAT in ms) was measured between the beginning of depolarization in an orthogonal lead and the $\mathrm{R}$ wave in the individual chest leads.

Statistical comparison was performed by Student's t-test and Mann-Whitney test.

\section{Results}

The results of 12 leads ECG are shown in Table 2. The heart rate in DM 1 patients was increased $(\mathrm{p}<0.002)$, QRS and QT interval shortened $(\mathrm{p}<0.009$; $\mathrm{p}<0.001)$ and $\mathrm{QTd}$ increased $(\mathrm{p}<0.001)$ in comparison with the controls. The Qtc interval (QT corrected for the heart rate) was not significantly prolonged in DM 1 patients.

Significant differences in the parameters of heart electric field between diabetic patients and control subjects during BSPM measurements are presented in Table 3. The absolute value of the maximum (extremum) in depolarization isopotential maps (DIPMmax) from the beginning of $\mathrm{Q}$ wave until the 30th ms of the QRS was more positive in DM 1 patients than in the controls (DIPMmax 30). But this parameter was less positive in the later phase of QRS (40th-80th ms of QRS DIPMmax 50 in Table 3). The minimum (extremum) in DIPM maps (DIPMmin) was more negative in DM 1 patients than in the controls during QRS.

The more negative minimum of depolarization isointegral map (DIIMmin) in DM 1 patients confirmed the findings in DIPM maps $(-48.2 \pm 19.4 \mu \mathrm{Vs}$ in DM 1 and $-33.7 \pm 15.5 \mu \mathrm{Vs}$ in controls in Table 3, $<<0.01$ ).

The depolarization isoarea map maximum from the beginning of $\mathrm{Q}$ wave until the 40th $\mathrm{ms}$ of depolarization (DIAMmax 40) was higher in DM 1 patients $(18.9 \pm 1.5 \mu \mathrm{Vs})$ than in controls $(14.3 \pm 0.9 \mu \mathrm{Vs}$, $\mathrm{p}<0.01)$. This finding has well corresponded to the DIPMmax values. The depolarization isoarea map minimum (DIAMmin 40) was more negative in DM 1 patients $(-11.6 \pm 2.2 \mu \mathrm{Vs})$ than in controls $(-6.5 \pm 4.6 \mu \mathrm{Vs}$, $\mathrm{p}<0.001)$ similarly as the DIPMmax and DIIMmax. The minimum in isointegral map of Q wave (Q-IIMmin) was more negative in DM 1 patients $(-22.8 \pm 2.8 \mu \mathrm{Vs})$ than in the controls $(-15.1 \pm 1.2 \mu \mathrm{Vs}, \mathrm{p}<0.03)$ similarly as the minimum in DIPM and DIIM maps. The amplitude of the $\mathrm{Q}$ wave (Q-IPMAM) was more negative in DM 1 patients $(-861.0 \pm 92.1 \mu \mathrm{V})$ than in controls $(-634.0 \pm 49.2 \mu \mathrm{V}$, $\mathrm{p}<0.03$ ). The activation time (ICHVAT), the speed of activation of the heart measured on the surface of thorax, was faster in DM 1 patients $(63.2 \pm 1.2 \mathrm{~ms})$ when compared to controls $(70.5 \pm 2.0 \mathrm{~ms}, \mathrm{p}<0.01$ in Table 3$)$. 
Table 3. The significant differences of heart electric field parameters in DM 1 patients and in controls measured by BSPM method.

\begin{tabular}{|c|c|c|c|}
\hline Parameter & Controls $(n=22)$ & DM $1(n=22)$ & $\mathbf{p}$ \\
\hline DIPMmax $10(\mu \mathrm{V})$ & $96.09 \pm 11.3$ & $122.64 \pm 7.9$ & 0.008 \\
\hline DIPMmax $30(\mu \mathrm{V})$ & $722.5 \pm 52.6$ & $965.6 \pm 79.9$ & 0.023 \\
\hline DIPMmin $40(\mu \mathrm{V})$ & $-829.6 \pm 131.3$ & $-1468.7 \pm 164.9$ & 0.001 \\
\hline DIPMmax $50(\mu V)$ & $1108.4 \pm 108.2$ & $815.8 \pm 78.9$ & 0.046 \\
\hline DIPMmin $50(\mu \mathrm{V})$ & $-1160.4 \pm 531.9$ & $-1510.0 \pm 110.8$ & 0.03 \\
\hline DIIMmin $(\mu V s)$ & $-33.6 .4 \pm 3.3$ & $-48.1 \pm 4$ & 0.01 \\
\hline RIPMmax $10(\mu \mathrm{V})$ & $168.8 \pm 26.1$ & $119.14 \pm 21.2$ & 0.017 \\
\hline RIPMmin $30(\mu V)$ & $-327.9 \pm 193.3$ & $-96.9 \pm 11.6$ & 0.041 \\
\hline RIPMmin $90(\mu V)$ & $-313.4 \pm 133.2$ & $-143.0 \pm 19.8$ & 0.029 \\
\hline RIPMmax $100(\mu \mathrm{V})$ & $248.3 \pm 38.9$ & $142.0 \pm 12.6$ & 0.013 \\
\hline RIPMmin $100(\mu \mathrm{V})$ & $-289.2 \pm 122.7$ & $-119.0 \pm 23.3$ & 0.006 \\
\hline$D I A M \max 40(\mu V s)$ & $14.2 \pm 0.92$ & $18.9 \pm 1.51$ & 0.011 \\
\hline DIAMmin $40(\mu V s)$ & $-6.5 \pm 1.0$ & $-11.6 \pm 2.25$ & 0.001 \\
\hline$Q-I I M\left(\mu V_{s}\right)$ & $-15.0 \pm 1.17$ & $-22.8 \pm 2.82$ & 0.039 \\
\hline$Q-I P M A M(\mu V)$ & $-634.2 \pm 49.2$ & $-861.2 \pm 92.1$ & 0.038 \\
\hline ICHVAT (ms) & $70.4 \pm 2.0$ & $63.2 \pm 1.5$ & 0.011 \\
\hline
\end{tabular}

Data are mean \pm S.E.M. DIPMmax, DIPMmin - maximum, minimum in depolarization isopotential map ( $\mu$ V). IPMmax, RIPMmin maximum, minimum in repolarization isopotential map $(\mu \mathrm{V})$. DIIMmin - minimum in depolarization isointegral map ( $\mu \mathrm{Vs})$. DIAMmax 40 , DIAMmin 40 - maximum, minimum in depolarization isoarea map from the beginning of QRS to 40th ms of depolarization - $\mu$ Vs. $\mathrm{Q}$-IPMAM - maximum amplitude of $\mathrm{Q}$ wave $(\mu \mathrm{V})$. ICHVAT - activation time between the onset of electrical activation registered by orthogonal leads $x, y, z$ and the thoracic surface ECG (ms).

This could well be explained by an activation of the sympathetic nervous system.

The repolarization isopotential map maximum (RIPMmax) was less positive and minimum (RIPMmin) less negative in DM 1 patients than in the controls (Table 3) showing the different rate of repolarization in DM 1 patients during the $T$ wave.

The QT interval was significantly shortened in all 96 thorax leads in DM 1 patients than in the controls thus confirming the activation of the sympathetic nervous system (data not shown).

\section{Discussion}

Our results showed the tachycardia, shortening of the QRS and QT intervals and increase of the dispersion of QT interval (Table 2) in DM 1 patients without cardiovascular complications. The prolongation of QTc was nonsignificant probably due to the small number of diabetic patients. Our work confirmed the previous findings registered by the classic 12-leads ECG (Pilati et al. 1981, Krahulec et al. 2002). The decrease in $\mathrm{T}$ wave amplitude in DM 1 patients (Krahulec et al.
2002) was confirmed in our results by the lower value of maximum and minimum in repolarization isopotential maps (RIPMmax, RIPMmin) in DM 1 patients in comparison with controls (Table 3). Unfortunately, we have no possibility to compare our present results obtained by measuring of heart electric field parameters using the BSPM method in DM 1 patients with another work in the literature (except of the 12-leads ECG) as we were the first who used this method for evaluating heart electric field in DM 1 patients.

The BSPM method was used in the ontogeny of healthy humans (Slavíček et al. 2001), in coronary artery disease (Kittnar et al. 1993), in hypertension (Tichý et al. 2001), or in depressive patients treated with antidepressants (Slavíček et al. 1998, Paclt et al. 2003, Kitzlerová et al. 2003, Kittnar et al. 2004), in panic disorder before treatment (Pišvejcová et al. 2002), or in late pregnancy and after delivery (Lechmanová et al. 2002).

The similar results of heart electric field parameters which we have obtained in the present work in DM 1 patients were also observed in the depressive patients treated with the tricyclic antidepressants 
(Slavíček et al. 1995, 1998, Paclt et al. 2003, Kitzlerová et al. 2003) or in panic disorder (Pišvejcová et al. 2002) due to activation of the sympathetic nervous system. On the other hand, ontogenic changes of the heart rate (the bradycardia in older healthy humans) have been characterized by different alterations in the parameters of heart electric field (Slavíček et al. 2001) than in the present work. The vectorcardiographic parameters were unchanged in our present work although the effect of dosulepine caused a deviation of the QRS axis (Kitzlerová et al. 2003) due to activation of the sympathetic nervous system.

QTd was evaluated using the method of BSPM. The decision to use a greater number of leads for the determination of QT dispersion helps to determine the QTd more accurately than the assessment with only 12 or even 6 precordial leads. The use of a low number of leads was undoubtedly the main cause of the repeatedly suggested poor reproducibility (Kautzner et al. 1994, Day et al. 1990). Enhanced accuracy for QT dispersion assessment from a 12-lead ECG in comparison with only 6 precordial leads was also reported (van de Loo et al. 1994, Higham and Campbell 1994).

Measurements performed in the present study indicate that type 1 diabetes causes an increase in the QT dispersion even in diabetic patients without any clinically evident microvascular and/or macrovascular complications. This finding is in agreement with that from our previous study (Lechmanová et al. 2002), where QT dispersion was measured using the same method on healthy female volunteers in a late phase of pregnancy. In the above study, we concluded that QT dispersion can reflect not only an increased risk of serious tachyarrhythmias, especially due to myocardial ischemia, but it can also be increased physiologically by a changed spatial arrangement of the chest organs, including the heart. In the present study, the results are very similar but, in the latter case, we suppose that the increased QT dispersion is a non-specific sign of a changed course of repolarization, which could reflect the changes in the tone of autonomic nervous system.

The non-specifity of QTd is supported by the fact that it corresponds to the dispersion of $\mathrm{T}$ wave amplitude (Havránek et al. 2004). We suppose that changed $\mathrm{T}$ wave shape does reflect the same abnormality as QTd does, as both of them could be non-specific signs of an attenuated repolarization pattern (and flattening of $\mathrm{T}$ wave is well known non-specific sign of a defective course of repolarization).
Diabetes mellitus can be considered as a vascular disease because it causes both microvascular and macrovascular complications. It is one of the most common chronic diseases in the world (Nathan et al. 1997). Cardiovascular diseases account for at least $66 \%$ of deaths in diabetic patients (Zimmet and Alberti 1997). Due to the sensitive neuropathy, the coronary artery disease in diabetic patients is frequently asymptomatic (Langer et al. 1991). This fact underlines the importance of laboratory testing. Twelve ECG leads at rest can be within normal limits even in an advanced stage of coronary artery disease (Wackers et al. 2004). Therefore, the stress test may play an important role in detection of significant coronary stenosis (Bigi et al. 2001, DeLorenzo et al. 2002). In this respect BSPM may be a useful tool in coronary ischemia diagnosis, however, there is not yet any available BSPM in asymptomatic diabetic patients.

In our present study, we have studied DM 1 patients without any clinically evident microvascular and/or macrovascular complications. These patients represent a group of young people with a very low probability of asymptomatic coronary artery disease. ECG changes including BSM results in our diabetic patients should therefore be interpreted carefully. Heart rate acceleration, shortening of QRS and QT intervals, significant changes of depolarization and repolarization in BSPM measurement can be explained by activation of the adrenergic system in diabetic patients and compared to nondiabetic subjects. The augmented sympathethic nervous activity is one of the assumptions for the development of arrhythmias and changes of ventricular repolarization (Abildskov 1985). However, no diabetic patients in our group fulfilled the criteria for autonomic neuropathy defined by the Ewing test or by a heart rate variability study (Alberti and Zimmet 1998).

The influence of autonomic neuropathy and of the left ventricle mass on BSPM should be addressed in future studies because these situations are frequently seen in diabetic patients. Finally the position of BSPM in coronary ischemia detection may be appreciated in asymptomatic diabetic patients with resting 12 leads ECG within normal limits using its association with the stress test (e.g. stress myocardial SPECT) or with coronary angiography.

It could be concluded that our results have confirmed a decreased parasympathetic to sympathetic tone ratio (tachycardia, shortening of the activation time) and revealed different depolarization and repolarization patterns in DM 1 patients. The differences in heart 
electric field parameters measured by BSPM method in DM 1 and in the controls show the importance of ECG examination of DM 1 patients in the prevention of cardiovascular diseases.

\section{Acknowledgements}

This study was partially supported by research grants GAUK 53/2004, 1ET201210527 and GACR 106/04/1181.

\section{References}

ABILDSKOV JA: Neural mechanisms involved in the regulation of ventricular repolarization. Eur Heart J 6 (Suppl D), 31-39, 1985.

ALBERTI KG, ZIMMET PZ: The WHO Consultation, definition, diagnosis and classification of diabetes mellitus and its complications. Part I: diagnosis and classification of diabetes mellitus. Provisional report WHO Consultation. Diabet Med 15: 539-553, 1998.

ALBERTI KG, ZIMMET PZ, DeFRONZO RA: International Textbook of Diabetes Mellitus. John Wiley, Ontario, 1978.

BECKMAN JA, CREAGER MA, LIBBY P: Diabetes and atherosclerosis: epidemiology, pathophysiology and management. JAMA 287: 2570-2581, 2002.

BIGI R, DESIDERI A, CORTIGIANI L, BAX JJ, CELEGON L, FIORENTINI C. Stress echocardiography for risk stratification of diabetic patients with known or suspected coronary artery disease. Diabetes Care 24: 16021607, 2001.

CHARVÁT J: Diabetes Mellitus and Macrovascular Complications (in Czech). Triton, Prague, Czech Republic, 2001.

CHARVÁT J, MICHALOVÁ K, TÁBORSKÁ K, CHLUMSKÝ J, KVAPIL M: Comparison of the exercise ECG and stress myocardial SPECT in detection of the significant coronary artery disease in the asymptomatic patients with diabetes mellitus type 2. Bratisl Lek Listy 105: 56-61, 2004.

DAY CP, MCCOMB JM, CAMPBELL RWF: QT dispersion: an indication of arrhythmia risk in patients with long QT intervals. Br Heart J 63: 342-344, 1990.

DELORENZO A, LIMA RS, SIQUEIRA-FILHO AG, PANTOJA MR. Prevalence and prognostic value of perfusion defects detected by stress technetium-99 sestamibi myocardial perfusion single-photon emission computed tomography in asymptomatic patients with diabetes mellitus and no known coronary artery disease. $\mathrm{Am} J$ Cardiol 90: 827-832, 2002.

FRANK E: An accurate, clinically practical system for spatial vectorcardiography. Circulation 13: 737-749, 1956.

HAVRÁNEK Š, MLČEK M, PACLT I, SLAVÍČEK J, KITTNAR O, DOHNALOVÁ A, BRIZMAN E, HÁLA P, KITZLEROVÁ E, PIŠVEJCOVÁ K: QT dispersion estimated from 80 body surface potential map leads and from standard 12-leads ECG in psychiatric patients treated with dosulepin. Prague Med Rep 105: 53-63, 2004.

HELLER SR: Abnormalities of the electrocardiogram during hypoglycaemia: the cause of the dead in bed syndrome? Int J Clin Pract Suppl 129: 27-32, 2002.

HIGHAM PD, CAMPBELL RWF: QT dispersion. Br Heart J 71: 508-510, 1994.

JAVORKA M, JAVORKOVA J, TONHAIZEROVA I, JAVORKA K: Parasympathetic versus sympathetic control of the cardiovascular system in young patients with type 1 diabetes mellitus. Clin Physiol Funct Imaging 25: 270274, 2005.

KANNEL WB, NEATON JD, WENWORTH D, THOMAS HE, STAMLER J, HULLEY SB, KJELSBERG MO: Overall and coronary heart disease mortality rates in relation to major risk factors in 325348 men screened for the MDFIT. Multiple Risk Factor Intervention Trial. Am Heart J 112: 825-36, 1986.

KAUTZNER J, GANG YI, CAMM AJ, MALIK M: Short- and long-term reproducibility of QT, QTc and QT dispersion measurement in healthy subjects. PACE 17: 928-937, 1994.

KITTNAR O, SLAVÍČEK J, VÁVROVÁ M, BARNA M, DOHNALOVÁ A, MÁLKOVÁ A, ASCHERMANN M, HUMHAL J, HRADEC J, KRÁL J: Repolarization patterns of body surface potential maps (BSPM) in coronary artery disease. Physiol Res 42: 123-130, 1993. 
KITTNAR O, PACLT I, MLČEK M, SLAVÍČEK J, DOHNALOVÁ A, HAVRÁNEK Š, BRIZMAN E, KITZLEROVÁ E, PIŠVEJCOVÁ K: QT dispersion and electrical heart field morphology in patients with dosulepin. Physiol Res 53: 379-386, 2004.

KITZLEROVÁ E, SLAVÍČEK J, PACLT I, PIŠVEJCOVÁ K, DOHNALOVÁ A: Plasma levels of dosulepin and heart electric field. Physiol Res 52: 319-325, 2003.

KRAHULEC B, MIKEŠ Z, BALAŽOVJECH I: The effect of cardiovascular autonomic neuropathy on resting ECG in type 1 diabetic patients. Bratisl Lek Listy 103: 54-58, 2002.

LANGER A, FREEMAN MR, JOSSE RG, STEINER G, ARMSTRONG PW: Detection of silent ischemia in diabetes mellitus. Am J Cardiol 67: 1037-1038, 1991.

LECHMANOVÁ M, KITTNAR O, MLČEK M, SLAVÍČEK J, DOHNALOVÁ A, HAVRÁNEK Š, KOLAŘíK M, PAŘÍZEK A: QT dispersion and T loop morphology in late pregnancy and after delivery. Physiol Res 51: 121$129,2002$.

MARQUES JL, GEORGE E, PEACEY SR, HARRIS ND, MACDONALD IA, COCHRANE T, HELLER SR: Altered ventricular repolarization during hypoglycaemia in patients with diabetes. Diabet Med 14: 648-654, 1997.

NATHAN DM, MEIGS J, SINGER DE. The epidemiology of cardiovascular disease in type 2 diabetes mellitus: how sweet it is... or is it? Lancet 350 (Suppl I): 4-9, 1997.

PACLT I, SLAVÍČEK J, DOHNALOVÁ A, KITZLEROVÁ E, PIŠVEJCOVÁ K: Electrocardiographic dosedependent changes in prophylactic doses of dosulepine, lithium and citalopram. Physiol Res 52: 311-317, 2003.

PAILLOLE C, RUIZ J, JULIARD JM, LEBLANC H, GOURGON R, PASSA P. Detection of coronary artery disease in diabetic patients. Diabetologia 38: 726-31, 1995.

PICKUP JC, WILLIAMS SG: Textbook of Diabetes. Blackwell Publishing, Oxford, 2003.

PILATI G, CIAVARELlA A, MARCHESINI G, ALLEGRO G, BARONI G, VANNINI P, PISI E: Abnormal cardiovascular reflexes in juvenile diabetics as preclinical signs of autonomic neuropathy. G Ital Cardiol 11: 2139-2143, 1981.

PIŠVEJCOVÁ K, PACLT I, SLAVÍČEK J, KITTNAR O, DOHNALOVÁ, A, KITZLEROVÁ, E: Electrocardiogram, vectocardiogram and body surface maps in patients with panic disorder. Physiol Res 51: 401-406, 2002.

RUZICSKA E, NAGY V, SARMAN B, SKOUMAL R, SOMOGYI A: Blood pressure volatility - a new parameter for determining blood pressure variability in type 1 diabetes mellitus. Orv Hetil 144: 1779-1784, 2003.

SLAVÍČEK J, PACLT I, KITTNAR O, DOHNALOVÁ A: Some electrocardiographic side effects of antidepressant drugs. Cor Vasa 37: 212-216, 1995.

SLAVÍČEK J, PACLT I, HAMPLOVÁ J, KITTNAR O, TREFNÝ Z, HORÁČEK BM: Antidepressant drugs and heart electrical field. Physiol Res 47: 297-300, 1998.

SLAVÍČEK J, KITTNAR O, NOVÁK V, TREFNÝ Z, HORÁČEK BM: ECG body surface isointegral and isoarea maps (BSM) in 30 and 60-year-old healthy humans. Sborn Lék 102: 369-374, 2001.

ŠTĚPÁNKOVÁ I, ŽĎÁRSKÁ, D, PELÍŠKOVÁ P, CHARVÁT J, SLAVÍČEK J, MLČEK M, MEDOVÁ E, KITTNAR O: ECG body surface mapping (BSM) in diabetic patients (type 1). Physiol Res 55: 45P, 2006.

ŠVORC P, WILK P, MURÁR J, PODLUBNÝ I, KUJÁNIK S, BRAČOKOVÁ I, MURÍN M: Circadian rhythm of the ventricular fibrillation threshold in female Wistar rats. Physiol Res 43: 355-358, 1994.

ŠVORC P, BRAČOKOVÁ I, PODLUBNÝ I: Relation of ventricular fibrillation threshold to heart rate during normal ventilation and hypoventilation in female Wistar rats: a chronophysiological study. Physiol Res 49: 711-719, 2000.

TICHÝ JA, SLAVÍČEK J, KITTNAR O, TROJAN S, ČERVENKA V, TREFNÝ Z, HOJEROVÁ M: Changes in systemic hemodynamics and ECG body surface potential mapping during treatment of essential hypertension. Noninvasive Cardiol Cardiovasc Rev Rep 22: 177-182, 2001.

VAN DE LOO A, ARENDTS W, HOHNLOSER SH: Variability of QT dispersion measurements in the surface electrocardiogram in patients with acute myocardial infarction and in normal subjects. Am J Cardiol 74: 1113$1118,1994$. 
WACKERS FJ, YOUNG LH, INZUCCHI SE, CHYUN DA, DAVEY JA, BARRET EJ, TAILLEFER R, WITTLIN SD, HELLER GV, FILIPCHUK N, ENGEL S, RATNER RE, ISKANDRIAN AE: Detection of silent myocardial ischemia in asymptomatic diabetic subjects, the DIAD study. Diabetes Care 27: 1954-1961, 2004.

ZELLWEGER MJ, PFISTERER ME: Silent coronary artery disease in patients with diabetes mellitus. Swiss Med Wkly 131: 427-432, 2001.

ZIMMET PZ, ALBERTI KG: The changing face of macrovascular disease in non-insulin-dependent diabetes mellitus: an epidemic in progress. Lancet 350 (Suppl I): 1-4, 1997.

\section{Corresponding author}

Otomar Kittnar, Institute of Physiology, First Medical Faculty, Charles University, Albertov 5, 12800 Prague 2, Czech Republic. E-mail: okittnar@1f1.cuni.cz 